September 2008

\title{
An approach to the failed ankle arthrodesis
}

Steven M. Raikin

Rothman Institute and Thomas Jefferson University

Venkat Rampuri

Rothman Institute

Follow this and additional works at: https://jdc.jefferson.edu/orthofp

Part of the Orthopedics Commons

Let us know how access to this document benefits you

\section{Recommended Citation}

Raikin, Steven M. and Rampuri, Venkat, "An approach to the failed ankle arthrodesis" (2008).

Department of Orthopaedic Surgery Faculty Papers. Paper 13.

https://jdc.jefferson.edu/orthofp/13

This Article is brought to you for free and open access by the Jefferson Digital Commons. The Jefferson Digital Commons is a service of Thomas Jefferson University's Center for Teaching and Learning (CTL). The Commons is a showcase for Jefferson books and journals, peer-reviewed scholarly publications, unique historical collections from the University archives, and teaching tools. The Jefferson Digital Commons allows researchers and interested readers anywhere in the world to learn about and keep up to date with Jefferson scholarship. This article has been accepted for inclusion in Department of Orthopaedic Surgery Faculty Papers by an authorized administrator of the Jefferson Digital Commons. For more information, please contact: JeffersonDigitalCommons@jefferson.edu. 


\section{An Approach to the Failed Ankle Arthrodesis}

\section{Introduction}

Ankle arthrodesis has been successfully used for end stage arthritis of the ankle, for well over a century [1]. It has proven to be successful in relieving pain [2-8] by eliminating motion and providing stability with a well aligned plantigrade foot. Arthrodesis has remained the gold standard for end stage post traumatic arthritis, against which other surgical procedures for ankle arthritis are compared for clinical and functional benefits $[9,10]$.

Originally devised for Poliomyelitis and tuberculosis of the ankle, the indications for ankle arthrodesis have changed over time. Current indications include isolated end stage arthritis from a post traumatic, post-infective, avascular necrosis or an inflammatory etiology. Fusion of a Charcot neuropathy of the ankle was previously avoided due to the high incidence of nonunion; however recent studies seem to show with the current improved methods of fusion, it is a reasonable option [11-13].

Fusion rates ranging from $80 \%$ to $100 \%$ have been reported in the literature [7], along with patient satisfaction rates over $80 \%$ [14]. Intermediate and long term studies however have shown functional deterioration over time [2-8]. Successful outcome often depends on the etiology for which the fusion was performed. Patients undergoing ankle arthrodesis after a bacterial infection or neuropathic ankle arthropathy will often have poor results in comparison to other etiologies $[15,16]$. Unrecognized involvement of adjacent joints in the arthritic process may lead to persistent pain despite successful fusion and should be 
evaluated prior to surgery with careful radiological assessment or by selective joint injections.

Detailed gait analysis done following an ankle arthrodesis has shown decreased cadence and stride length with decreased range of motion of both the hind and mid foot during the stance and swing phases of the gait [8]. This loss of motion deteriorates further with developments of subtalar and mid foot arthritis $[8,15]$ leading to long term failures. Thus it is important to recognize that in light of its success and failures, ankle arthrodesis are a salvage option in patients with pain and stiffness [17].

Said et al [18] in their study found that all their failed ankle fusions required revision surgeries; however re-operation rates for failed fusions have been quoted to range from $50 \%$ to $70 \%[14,19]$. Complications of ankle arthrodesis could be broadly categorized into early or short term, intermediate and long term. These have ranged from wound related complications, neurovascular injuries, infections, malunions from malpositioning, nonunions, adjacent joint arthritis, limb shortening and limb atrophy. This article reviews various complications of the open arthrodesis procedures and discusses the potential causes of these problems. It also addresses their prevention and the options of management of these, often difficult problems.

\section{Short term complications}

Post operative recuperation after a successful ankle arthrodesis includes a long rehabilitation process, with most people returning to early activities at an average of twelve months after the fusion [14]. Short term or early complications 
could be defined as those occurring from the immediate post operative period to the first six months after surgery. Early complications predominantly involve wound related problems and infections. Other associated complications such as nerve injury, complex regional pain syndrome, deep vein thrombosis, pulmonary embolism and other medical problems in the early postoperative period can also delay a successful rehabilitation.

\section{Wound related problems}

Wound related complications seem to be in direct relation to the surgical technique and handling of soft tissues during the surgery. Many patients have had prior surgery with multiple scars and adhesions within the soft tissue envelope around the ankle. The surgeon should attempt to use prior incisions when possible, and create adequate thickness of the skin flaps to optimize vascular supply to the skin edges. When it is not possible to use a prior incision, care should be taken to ensure adequate angiosomal circulation to the skin bridge between incisions to prevent necrosis and breakdown, which can lead to infection.

Most wound problems involve delayed wound healing or a superficial wound infection. Superficial infection of the surgical incision or the pin sites in external fixation methods have been reported as occurring in $40 \%$ to $50 \%$ of the cases [5, 20-23]. Most of these do not case long term morbidity yet need to be managed with care. Prophylactic measures such as pre-operative antibiotics, a meticulous sterile surgical technique, and prevention of excessive traction of skin helps to prevent these problems. 
Unless infection is present, antibiotics should not be started and local wound care will usually suffice. In the presence of a superficial infection, a broad spectrum oral antibiotic may suffice together with dressing changes. Superficial wound cultures are controversial due to high contamination rates, but may be useful in directing antibiotic selection.

It is important to recognize the high risk patients such as those patients with dysvascular skin, rheumatoid or diabetic patients, patients on long term steroids and patients undergoing revision surgeries. If treated early these superficial wound infections tend to heal well without further problems, a delay in recognizing these infections could result in disastrous results such as amputations [18].

\section{Deep Infection}

Deep Infections following ankle fusion could lead to deep sepsis and osteomeylitis, with disastrous consequences [18]. Recognition of such conditions is essential as these are not amenable to simple oral antibiotics. A thorough surgical irrigation and debridement of the wound combined with an adequate (usually six week) course of intravenous antibiotics is necessary to treat the infection. If the infection involves the internal hardware, removal followed by stabilization with an external fixation device can salvage the arthrodesis and allow successful fusion to still occur [24]. The remaining wound may not be able to be primarily closed and should be managed with vacuum assisted secondary closure [25] or application of a myocutaneous flap. The rates of amputation in patients 
with persistent osteomyelitis and an ongoing infection with drainage despite above measures could be as high as $50 \%$ [18, 20, 23, and 26]. This is more so in the case of fusions done in the face of an existing septic process.

\section{Intermediate term complications}

Intermediate term complications could be defined as those occurring between the first six months to a year after the fusion. During this period the fusion is consolidated into a bony construct, allowing the patients progressively increase their weight bearing status, and there by letting them to return to their activities. Malunions due to malpositioning and nonunion are the two major complications during this period. Other minor complications during this period include chronic edema, stress fractures and calluses.

The ideal position in which the ankle is fused has changed over time [27]. Previously the ankle was fused in a more equinus position to allow patients to wear shoes with heels. This has been discontinued, as gait studies demonstrated a vaulting gait pattern with a recurvatum thrust at the knee $[3,28]$. The current accepted position for fusion involves the ankle being held in neutral dorsiflexion / plantar flexion, $5^{0}$ of valgus, $5^{0}$ to $10^{0}$ of external rotation and slightly posteriorly displaced talus relative to the tibia $[3,27]$. The overall alignment of foot to the rest of limb should be assessed and compared to the opposite side before accepting the fusion. In a gait analysis done by Morrey et.al, this position was shown to produce a more normal pattern of gait and decrease the stress around the 
knee [3]. Posterior placement of the talus under the tibia has been described to reduce the anterior lever arm of the foot under the arthrodesis. While anterior placement, which can cause difficulties with the foot clearing the ground during swing phase of the gait, should be avoided, the theoretical advantage of posterior placement has not proved to be clinically relevant.

\section{Malunions}

\section{Sagittal plane deformities}

Variations from the accepted positions of alignment hence could be labeled as malunions or malpositions. Excessive dorsiflexion or plantar flexion beyond plantigrade position, could transform into flexion or extension deformities of the knee leading to gait disturbances.

An ankle fused in an equinus position results in a vaulting gait secondary to the recurvatum deformity at the knee (figure 1), occurring as a compensatory mechanism by which the patient clears the foot off the ground during the gait cycle. Such a pathological gait not only puts undue stress across the knee but also at the anterior tibia and the midfoot resulting in stress fractures and metatarsalgia. Alternately the patients may externally rotate their leg while walking, putting increased stress on the medial aspect of the knee and on the hind foot. Treatment of a symptomatic equinus deformity starts with the use of solid ankle cushion heel $(\mathrm{SACH})$ shoe to improve mechanics and alleviate symptoms. Surgery is offered to those who remain symptomatic despite these measures. 
An ankle fused in a dorsiflexed position will result in increased pressure on the heel pad causing pain and potential breakdown. Gait alterations include ambulating with a flexed knee to maintain a plantigrade foot. This can be corrected by using a rocker bottom sole shoe, with surgery being indicated in recalcitrant cases.

The revision surgery for sagittal plane deformities involves realignment osteotomies through the fusion mass. These can be done through closing wedge or opening wedge realignment procedures, with closing wedge osteotomies being more frequently used. These diminish stretch to associated nerves and the soft tissue and allow bone to bone approximation with high fusion rates. The disadvantage however, is that further limb shortening will occur as a result of the bony resection from the osteotomy site. Dome shaped osteotomies are technically more challenging but are less likely to affect limb length. Correction of an equinus deformity thus involves either a posterior opening wedge or an anterior closing wedge osteotomy (figure 2), while dorsiflexion malunion can be corrected with either an anterior opening or a posterior closing wedge osteotomy. Determination of the approach often lies with several factors such as prior incisions and associated leg length discrepancies. The amount of bone to be resected and the place of resection often need to be individualized from patient to patient.

\section{Coronal plane deformities}


Positioning of the ankle fusion in greater than $5^{\circ}$ of valgus or any degree of varus can cause undue stresses across the hind foot (figure 3) and the knee. An excessive valgus position will cause undue stress on the posterior tibial tendon and the ligamentous structures on the medial aspect of the ankle resulting in development of a flat foot posture. These forces could transmit proximally stressing the inner aspect of the knee. Walking on a foot aligned in excess valgus also puts undue stress on the medial column and the $1^{\text {st }}$ TMT joint complex resulting in stress fractures or premature arthritis in this area. Initial use of medial hind foot wedge orthotic inserts to tilt the foot into varus should be attempted. Failure requires surgical correction utilizing a medial closing wedge osteotomy of the fusion mass. A transfibular approach with a lateral wedge is also an option if the prior incisions dictate the approach.

No degree of varus alignment is tolerated following arthrodesis of the ankle joint. This will result in undue stress on the subtalar joint and the peroneal tendons, lateral ligamentous structures and the lateral column of the foot. This may eventually result in stress fractures of the fifth metatarsal bone, premature subtalar joint arthritis or peroneal tendon pathology. Again, initial treatment is with an orthotic insert with a lateral posting to drive the foot into a neutral position, which can be combined with a lateral flare to redistribute the pressure on the bottom of the foot. Surgical management would include a lateral closing wedge osteotomy of the fusion mass to correct the deformity.

Chronic deformity will result in secondary changes in the hind foot and forefoot alignment. Many patients will require additional bony and soft tissue 
procedures around the foot so as to obtain a well aligned plantar grade foot after realignment osteotomy. Correction of any associated rotational elements is also feasible with this approach.

\section{Rotational and complex deformities}

Excess internal or external rotation of the foot in relation to the tibia could lead to a compensatory torsional defect of the tibia resulting undue torsional stress on the knee. Rotation deformities are often associated with some other planar deformities and often require adequate surgical planning. Although most of these malpositions or mal-alignments can be diagnosed by sheer clinical examination, it is essential to do a gait analysis along with a CT scan comparison to the unaffected side to assess the alignment before a revision surgery is undertaken for these patients. These scans help in identifying the direction of malunions, as it often could be multiplanar instead of isolated sagittal or coronal planar deformity. Correction of multiplanar deformities may require multiplanar osteotomies and are often complex to perform. These may be best corrected by external devices such as an Illizarov or a Taylor spatial frame (Smith and Nephew, Memphis TN) type of construct. Recently conversion to a total ankle replacement has been shown to relieve symptoms of ankle fusion malunions, while obtaining correction of the deformity [29]. The long term efficacy of these procedures is however unknown and amputation rates of $13 \%$ have been reported [29].

\section{Nonunions}


With improving methods of fixation, rates of unions are also improving, however nonunion still remains to be one of the leading causes of failures. Fusion usually occurs within three months of surgery, with delayed union defined as those taking three to six months, and nonunions as taking more than six months to fuse. Delayed union seen radiographically or suggested by persistent weight bearing pain in the ankle region, is managed by prolonged periods of immobilization and protected weight bearing. The addition of an external bone stimulator can be used to promote maturation of the fusion mass and advance the fusion.

Nonunions of the ankle arthrodesis are often painful and hence require a corrective revision surgery. Although there are several risk factors for nonunion, one of the leading causes is the etiology for which the fusion was performed. A recent metaanalysis described a nonunion rate of $10 \%$, with $65 \%$ of revision surgeries performed on failed ankle fusion being done to treat nonunions [31]. Historically nonunion rates have been reported to occur from $<5 \%[3,14,31,32]$ to $41 \%$ [26, 33], however with current improved methods of fixation the union rates have improved to $>90 \%[34,35]$. However preoperative infection [36], sensory neuropathy [19, 22, and 37] and AVN of the talus [38] seem to be affected with higher rates of nonunion (as high as 100\%). Among patients with post traumatic arthritis, high energy fractures resulting in talar dome fractures [38, 39] tibial plafond fractures [20,38] and those with open fractures also have higher rates of nonunion. Other historical risk factors associated with nonunions include, a history of diabetes and or renal disease or other major medical co-morbidities 
[38], history of smoking tobacco [40, 41], Rheumatoid arthritis [42], Psychiatric ailment [42] and a previous history of subtalar arthrodesis [43]. Other intra operative factors such as strength and method of fixation, bone defects and bone loss, poor bony apposition and bony preparation during fixation could all result in failures [42]. Similarly post operative factors such as inadequate immobilization after surgery, poor compliance could adversely affect union rates as well.

\section{Approach to Nonunions}

Treatment of a nonunion depends on the symptoms that the patient experiences. A revision surgery is indicated only in patients with a painful nonunion. A nonunion in a patient with neuropathy, if stable and asymptomatic is often best treated with bracing [44]. Most of the nonunions however ultimately require a revision surgery.

Accurate identification and diagnosis of the etiology behind a nonunion is essential before a revision surgery is under taken. While a certain percentage of nonunions will occur without a definitive underlying cause, a potential cause should always be excluded and reversed prior to revision surgery. Nonunion will usually occur as a result of either inadequate surgical technique at the index procedure (poor joint preparation or inadequate fixation); an inadequate healing milieu; or an infection. The process of critical analysis begins with a thorough history and physical examination, including a review of the previous surgical procedure. If the nonunion is a result of a poor surgical technique (figure 4), this 
may be the easiest to revise with a takedown on the nonunion, appropriate joint preparation, bone grafting and rigid fixation.

Patient associated risk factors can influence the healing environment increasing the risk of nonunion. While some factors such as age and neuroarthropathy cannot be altered, the surgeon should assess and correct all those factors, which can be improved. Cigarette smoking is a leading cause of fusion nonunions [40], and patients should be convinced to discontinue smoking before undertaking any revision surgery. Newer medications such as varenicline (Chantix $\left.{ }^{\mathrm{TM}}\right)$ together with counseling can assist the patient with their cessation program without the continued use of nicotine infused through traditional patches and gums. Although there is no evidence whether temporary smoking cessation prevents nonunion; it is anecdotally felt that discontinuation of cigarette smoking at least one to two weeks prior to surgery (and continued after surgery) may improve the micro-circulation. On a similar note rheumatoid patients are also advised to with hold immunosuppressant medication for two weeks before and two weeks after surgery, despite the literature supporting the fact that these medications do not increase the risk of nonunions or infections [45].

Diabetic patients should be counseled on the importance of a normal blood sugar levels prior to and after the surgery, as this has a direct bearing on the union. Patients with co morbidities should be optimized by their medical team before a revision surgery is under taken. Nutrition should be optimized and a prealbumen level of greater than $18 \mathrm{mg} / \mathrm{dl}$ is preferable before surgery is undertaken. In the absence of infection or osteonecrosis, once these factors are corrected, a 
standard type revision arthrodesis can be undertaken. This is performed with minimal soft tissue stripping, removal of all fibrous tissue from the nonunion site down to bleeding trabecular bone, use of autologous or allograft type of bone grafting, and appropriate rigid fixation. Strict adherence to compliance with post operative restrictions must be reinforced and adhered to including restricted weight bearing and external support until full consolidation which may take four to six months. Internal or external bone stimulation has not been found to be useful in an established nonunion [46], but may be useful following revision surgery.

An ankle nonunion that swells up with erythema and is warm to touch is an infective nonunion until proven otherwise. Investigation of an infected nonunion starts with a serological workup, including a full blood count (CBC), erythrocyte sedimentation rate (ESR) and a C-reactive protein (CRP). Although an elevated ESR and CRP are not diagnostic in itself, they are important indicators of infection and can be a useful baseline in monitoring treatment. Aspiration of nonunion is diagnostic in only $50 \%$ to $60 \%$ [47] of the cases; however it is the most specific test that yields direct information, which helps in management of these conditions. Imaging studies are often not specific enough to elucidate the cause of nonunion, but form an important part in the pre-surgical planning. Radiological studies often begin with a series of weight bearing x-rays, often supplemented by a CT scan looking for osseous defects. A contrast enhanced MRI scan may sometimes be useful in identifying osteonecrosis of the talus as an 
etiology of the nonunion. Nuclear scans are often mis-utilized, however a negative technetium bone scan can help rule out septic nonunion (although these often demonstrate increased activity in any nonunion and are poorly specific for infection). Indium-111 or Ceretec labeled white blood infusion scans have a higher specificity in diagnosing infected nonunions.

Confirmed infected nonunions require surgical management. In majority of the cases these require a staged correction [48-51], first eliminating the infection and subsequently treating the nonunion. This involves an initial removal of hardware, together with resection of all the infected pseudarthrosis tissue along with debridement of the nonviable sclerotic osseous elements. Remaining defects are filled with antibiotic impregnated bone cement beads and a course of intravenous organism specific antibiotic management is initiated, usually continued for at least six weeks. The second procedure is performed once the infection has been eradicated. If uncertainty persists, a frozen section biopsy can be taken at the second surgery and evaluated before insertion of internal fixation. If positive, a repeat debridement, irrigation and antibiotic cement bead insertion is performed. If the infection has been eradicated, bone grafting and filling all the osseous defects during the second stage is important, to provide adequate fixation and stimulus for a union.

The type of fixation required to achieve this could be either external or internal. Although there have been no prospective randomized controlled trials 
comparing the two methods, there is an inclination for external fixators, as it avoids placement of any foreign material at the site of fusion [52]. External fixation could be in the form of a circular skinny wire type frame (figure 5) or other unilateral or triangular frames constructs placed with compression across the joint area. External fixators offer some other advantages such as ease of caring for wound and soft tissue related problems, ability to correct three dimensional deformities including limb length inequalities and ability to bear weight early [24]. Potential problems and difficulties include pin tract infections, knee contractures or stiffness and secondary surgery for removal of the frame [24]. When the bone stock is adequate for a good internal fixation, fusion using large canulated screws in a cross screw fashion with bone grafting could be attempted. This fixation could be supplemented by either a rigid plating device or an external fixation for additional support and stability. Such choices often depend on the intra operative stability as assessed by the surgeon and the exposure required for the revision. An alternative approach is to perform one stage procedure with extensive debridement of infected and nonviable tissue followed by the immediate application of a compression external fixation device.

Patients who have had multiple revision surgeries for septic nonunion are some times better off with a below knee amputation and a prosthesis, especially when the bone loss is substantive [29].

An additional cause of aseptic nonunion of ankle arthrodesis is talar osteonecrosis. Revision surgery may require large portions of the talus to be removed until viable healing surfaces are obtained. These patients often do better 
with other salvage procedures such as tibiotalocalcaneal (TTC) arthrodesis or a tibiocalcaneal arthrodesis. Autologous bone graft supplementation and augmenting bone stimulators may increase the fusion rate of these procedures. Kitaoka et.al, reported on 19 patients undergoing this procedure with a fusion rate of $84 \%(16 / 19)$, but only $68 \%$ of patients rating their results as good or excellent [53]. Although both the above procedures can be performed either as open procedures with rigid internal fixation methods by cross screw technique and or rigid plating, recent studies have shown to achieve comparable results with lower complication rates using a retrograde nailing [54].

\section{Long term complications}

\section{Adjacent joint arthritis}

Adjacent segment disease after a fusion is a well proven and well documented entity in the spinal literature. Coester et.al, in their long term follow up study showed that after a mean follow-up period of twenty two years after an ankle arthrodesis, all patients had radiographic features in the surrounding joints suggestive of degenerative arthritis [6]. They reason that, due to increased functional demands and stresses on the surrounding joints after an arthrodesis there is an increase in abnormal motion and chronic loading of these joints leading to the development of osteoarthritis. The joints involved in their series included subtalar joint (figure 6), talonavicular joint, tarsometatarsal joint, naviculocuneiform, calcaneocuboid and $1^{\text {st }}$ MTP joint, with decreasing order of prevalence. Although they found correlation between foot function and the grade 
of the degenerative changes on the x-ray, they could not correlate pain and grade of the arthritis. Thus arguably ankle arthrodesis still stands as a standard treatment, with a caveat that foot function does deteriorate with time. Deterioration in function along with increasing pain is often difficult to deal with by bracing alone. A surgical option however involves fusion of the adjacent joints. The results of such pantalar fusions are often guarded and fraught with complications $[49,55]$.

\section{Leg length inequalities}

Limb length is often compromised during an attempted ankle arthrodesis to achieve a solid union. Post operatively, limb muscle atrophy occurs as a result of long periods of immobilization. Limb shortening and Limb atrophy are thus expected outcomes at the end of a successful ankle arthrodesis. Several authors have shown through studies that leg length inequalities up to $2.5 \mathrm{~cm}$ or one inch are often well tolerated by patients, through the use of shoe lifts $[56,58]$. If the limb length inequality however happens to be greater than $3.0 \mathrm{~cm}$ then a surgical option is the treatment of choice. Paley et.al in his article on treatment of malunions and nonunions after an ankle fusion has shown that this could effectively be done with the help of a circular fine wire frame with good predictable results [24]. He describes this technique using distraction osteogenesis proximally closer to the knee (with a revision ankle arthrodesis at the distal end if an associated nonunion or malunion is present). Additionally, with the help of the circular frame it is often not only possible to achieve limb length correction but 
also to correct any three dimensional or multiplanar problems at the ankle simultaneously.

\section{Ankle arthroplasty- a salvage option}

In patients with painful ankle arthrodesis, with or without a nonunion, in the absence of infection, an ankle arthroplasty is a possible salvage option. This is reserved for patients with adequate bone stock remaining to support an arthroplasty and allow for adequate ingrowth fixation. This includes patients with associated degenerative changes in the subtalar joints who would otherwise require a pantalar arthrodesis, which requires the oxygen consumption for gait akin to a patient with a below the knee or transtibial amputation [49, 55]. Greisberg et.al, in their series of 23 patients who had undergone such a conversion from fusion to total ankle arthroplasty reported overall higher satisfaction scores in all the patients after conversion to a total ankle. They did demonstrate a higher AOFAS hind foot scores for the group converted because of associated subtalar arthritis than those done for a painful fusion [29]. Similarly Barg and Hintermann recently reported on converting 29 painful ankle arthrodeses (27 for pain, two for nonunion) to ankle arthroplasty utilizing a three component system with high patient satisfaction regarding pain relief and regained function [57].

\section{Summary}


With evolved techniques and methods of fixation, ankle fusion has become a successful surgery with high fusion rates and predictably high satisfaction rates. As a result, arthrodesis of the ankle remains the gold standard for surgical management of end stage ankle arthritis. Complications and failures do however occur for various reasons as reviewed in the article. These can often be avoided or reduced with a proper surgical planning and technique. Proper patient selection thus becomes a key to successful surgery. The surgical techniques involved in both the primary fusion and as well as the salvage options are technically challenging, hence should be undertaken by orthopedic surgeons well trained within the foot and ankle subspecialty. A surgeon performing a revision arthrodesis must also be well versed with all the salvage options, with an in depth understanding of the mechanics, alignment and function of the ankle foot complex. A well thought out approach to the failed ankle arthrodesis can result in return to function and successful outcomes. A below the knee amputation remains the final salvage for the recurrently failed ankle arthrodesis. 


\section{Figure Legends:}

Figure 1: Clinical picture of a patient whose ankle has been fused in equinus. Note the recuvatum of the knee required to allow the foot to be plantargrade on the floor.

Figure 2A: Lateral radiograph of the ankle fused in equinus. Lines are drawn to represent the planned corrective anterior closing wedge osteotomy. The proximal osteotomy cut is perpendicular to the long axis of the tibia, while the distal cut is parallel to the floor.

Figure 2B: Lateral radiograph showing final correction after successful osteotomy and revision arthrodesis with ankle in neutral alignment.

Figure 3: CT scan of an ankle fused in valgus, with subsequent lateral subluxation and secondary valgus arthritis of the subtalar joint of the hindfoot.

Figure 4: Anetro-posterior radiograph demonstrating inadequate joint preparation and fixation resulting in this nonunion of an ankle fusion nine months out from surgery.

Figure 5: Lateral radiograph demonstrating a successful revision fusion of an infected nonunion of a prior attempted arthrodesis, utilizing a skinny wire type external fixator devise.

Figure 6: Lateral radiograph demonstrating subtalar arthritis eight year following an arthrodesis of the ankle. 


\section{References.}

1. Albert E. Zur Resektion des Kniegelenkes. Wien Med. Press. 1879:20:7058.

2. Ahlberg A, Henricson AS. Late results of ankle fusion. Acta Orthop Scand 1981;52:103-5.

3. Mazur JM, Schwartz E, Simon SR. Ankle arthrodesis. Long-term follow-up with gait analysis. J Bone Joint Surg Am 1979;61:964-75.

4. Boobbyer GN. The long-term results of ankle arthrodesis. Acta Orthop Scand 1981;52:107-10.

5. Lynch AF, Bourne RB, Rorabeck CH. The long-term results of ankle arthrodesis. J Bone Joint Surg Br 1988;70:113-6.

6. Coester LM, Saltzman CL, Leupold J, Pontarelli W: Long-term results following ankle arthrodesis for post-traumatic arthritis. J Bone Joint Surg Am 2001;83-A(2):219-28.

7. Muir DC, Amendola A, Saltzman CL. Long-term outcome of ankle arthrodesis. Foot Ankle Clin 2002;7(4):703-8.

8. Thomas R, Daniels TR, Parker K. Gait analysis and functional outcomes following ankle arthrodesis for isolated ankle arthritis. J Bone Joint Surg Am 2006;88(3):526-35.

9. Saltzman CL. Perspective on total ankle replacement. Foot Ankle Clin 2000;5(4):761-75.

10. Neufeld SK, Lee TH. Total ankle arthroplasty: indications, results, and biomechanical rationale. Am J Orthop 2000;29(8):593-602. 
11. Kile TA, Donnelly RE, Gehrke JC, Werner ME, Johnson KA.

Tibiotalocalcaneal arthrodesis with an intramedullaary device. Foot Ankle Int 1994;15(12):669-73.

12. Papa J, Myerson M, Girard P. Salvage, with arthrodesis, in intractable diabetic neuropathic arthropathy of the foot and ankle. J Bone Joint Surg Am 1993;75(7):1056-66.

13. Pinzur MS, Kelikian A. Charcot ankle fusion with a retrograde locked intramedullary nail. Foot Ankle Int 1997;18(11):699-704.

14. CD Morgan, JA Henke, RW Bailey, and H Kaufer: Long-term results of tibiotalar arthrodesis. J Bone Joint Surg. Am 1985; 67: 546 - 550.

15. Fuchs S, Sandmann C, Skawara A, Chylarecki C. Quality of life 20 years after arthrodesis of the ankle. A study of adjacent joints. J Bone Joint Surg $\operatorname{Br} 2003 ; 85(7): 994-8$.

16. Salem KH, Kinz L, Schmelz A. Ankle arthrodesis using Ilizarov ring fixators: a review of 22 cases. Foot Ankle Int 2006;27(10):764-70.

17. Thomas R, Daniels TR. Ankle arthritis. J Bone Joint Surg Am 2003;85$\mathrm{A}(5): 923-36$.

18. Said E, Hunka L, Siller TN. Where ankle fusion stands today. J Bone Joint Surg Br 1978;60-B(2):211-4.

19. Lance EM, Paval A, Fries I, Larsen I, Patterson RL Jr. Arthrodesis of the ankle joint. A follow-up study. Clin Orthop Relat Res 1979;(142):146-58. 
20. Kenzora JE, Simmons SC, Burgess AR, Edwards CC. External fixation arthrodesis of the ankle joint following trauma. Foot Ankle 1986;7(1):4961.

21. Morrey BF, Wiedeman GP. Complications and long-term results of ankle arthrodeses following trauma. J Bone Joint Surg Am 1980;62(5):777-84.

22. Ratliff AH. Compression arthrodesis of the ankle. J Bone Joint Surg Br 1959;41-B:524-34.

23. Scranton PE, Fu FH, Brown TD. Ankle arthrodesis: a comparative clinical and biomechanical evaluation. Clin Orthop Relat Res 1980;(151):234-43.

24. Katsenis D, Bhave A, Paley D. Treatment of malunion and nonunion at the site of an ankle fusion with the Ilizarov apparatus. J Bone Joint Surg Am 2005;87(2):302-9.

25. Mendonca DA, Cosker T, Makwana NK. Vacuum-assisted closure to aid wound healing in foot and ankle surgery. Foot Ankle Int 2005;26(9): 761766.

26. Hagen RJ. Ankle arthrodesis. Problems and pitfalls. Clin Orthop Relat Res 1986;(202):152-62.

27. Buck P, Morrey BF, Chao EY. The optimum position of arthrodesis of the ankle. A gait study of the knee and ankle. J Bone Joint Surg Am $1987 ; 69(7): 1052-62$.

28. King HA, Watkins TB, Samuelson KM. Analysis of foot position in ankle arthrodesis and its influence on gait. Foot Ankle 1980;1(1):44-9. 
29. Greisberg J, Assal M , Flueckiger G, Hansen ST. Takedown of ankle fusion and conversion to total ankle replacement. Clin Orthop Relat Res 2004;(424):80-8.

30. Haddad SL, Coetzee JC, Estok R, Fahrbach K, Banel D, Nalysnyk L. Intermediate and long-term outcomes of total ankle arthroplasty and ankle arthrodesis. A systematic review of the literature. J Bone Joint Surg Am 2007;89(9):1899-905.

31. Scranton PE. Use of internal compression in arthrodesis of the ankle. J Bone Joint Surg Am 1985;67(4):550-5.

32. Stewart MJ, Beeler TC, McConnell JC. Compression arthrodesis of the ankle. Evaluation of a cosmetic modification. J Bone Joint Surg Am $1983 ; 65(2): 219-25$.

33. Hallock H. Arthrodesis of the ankle joint for old painful fractures. J Bone Joint Surg Am 1945; 27: 49 - 58.

34. Monroe MT, Beals TC, Manoli A. Clinical outcome of arthrodesis of the ankle using rigid internal fixation with cancellous screws. Foot Ankle Int 1999;20(4):227-31.

35. Sowa DT, Krackow KA. Ankle fusion: a new technique of internal fixation using a compression blade plate. Foot Ankle 1989;9(5):232-40.

36. Cierny G, Cook WG, Mader JT. Ankle arthrodesis in the presence of ongoing sepsis. Indications, methods, and results. Orthop Clin North Am 1989;20(4):709-21. 
37. Hayes JT, Gross HP, Dow S. Surgery for paralytic defects secondary to myelomeningocele and myelodysplasia. J Bone Joint Surg Am 1964;46:1577-97.

38. Frey C, Halikus NM, Vu-Rose T, Ebramzadeh E. A review of ankle arthrodesis: predisposing factors to nonunion. Foot Ankle Int 1994;15(11):581-4.

39. Anderson JG, Coetzee JC, Hansen ST. Revision ankle fusion using internal compression arthrodesis with screw fixation. Foot Ankle Int 1997;18(5):300-9.

40. Cobb TK, Gabrielsen TA, Campbell DC, Wallrichs SL, Ilstrup DM. Cigarette smoking and nonunion after ankle arthrodesis. Foot Ankle Int 1994;15(2):64-7.

41. Haverstock BD, Mandracchia VJ. Cigarette smoking and bone healing: implications in foot and ankle surgery. J Foot Ankle Surg 1998;37(1):6974.

42. Kitaoka HB, Anderson PJ, Morrey BF. Revision of ankle arthrodesis with external fixation for non-union. J Bone Joint Surg Am 1992;74(8):1191200.

43. Perlman MH, Thordarson DB. Ankle fusion in a high risk population: an assessment of nonunion risk factors. Foot Ankle Int 1999;20(8):491-6.

44. Pinzur MS. Current concepts review: Charcot arthropathy of the foot and ankle. Foot Ankle Int 2007;28(8):952-9. 
45. Bibbo C, Goldberg JW. Infectious and healing complications after elective orthopaedic foot and ankle surgery during tumor necrosis factor-alpha inhibition therapy. Foot Ankle Int 2004;25(5):331-5.

46. Saltzman C, Lightfoot A, Amendola A. PEMF as treatment for delayed healing of foot and ankle arthrodesis. Foot Ankle Int 2004;25(11):771-3.

47. Perry CR, Pearson RL, Miller GA. Accuracy of cultures of material from swabbing of the superficial aspect of the wound and needle biopsy in the preoperative assessment of osteomyelitis. J Bone Joint Surg Am 1991;73(5):745-9.

48. Saltzman CL. Salvage of diffuse ankle osteomyelitis by single-stage resection and circumferential frame compression arthrodesis. Iowa Orthop J 2005;25:47-52.

49. Acosta R, Ushiba J, Cracchiolo A. The results of a primary and staged pantalar arthrodesis and tibiotalocalcaneal arthrodesis in adult patients. Foot Ankle Int 2000;21(3):182-94.

50. Richter D, Hahn MP, Laun RA, Ekkernkamp A, Muhr, Ostermann PA. Arthrodesis of the infected ankle and subtalar joint: technique, indications, and results of 45 consecutive cases. J Trauma 1999;47(6):1072-8.

51. Thordarson DB, Patzakis MJ, Holtom P, Sherman R. Salvage of the septic ankle with concomitant tibial osteomyelitis. Foot Ankle Int 1997;18(3):151-6. 
52. Kollig E, Esenwein SA, Muhr G, Kutscha-Lissberg F. Fusion of the septic ankle: experience with 15 cases using hybrid external fixation. J Trauma 2003;55(4):685-91.

53. Kitaoka HB, Patzer GL. Arthrodesis for the treatment of arthrosis of the ankle and osteonecrosis of the talus. J Bone Joint Surg Am 1998;80(3):3709.

54. Boer R, Mader K, Pennig D, Verheyen CC. Tibiotalocalcaneal arthrodesis using a reamed retrograde locking nail. Clin Orthop Relat Res 2007;463:151-6.

55. Papa JA, Myerson MS. Pantalar and tibiotalocalcaneal arthrodesis for posttraumatic osteoarthrosis of the ankle and hindfoot. J Bone Joint Surg Am 1992;74(7):1042-9.

56. Gross RH. Leg length discrepancy: how much is too much? Orthopedics 1978;1(4):307-10.

57. Barg AJ, Hinterman B. Take Down of Painful Ankle Fusion and Conversion into Total Ankle Arthroplasty. AAOS 2008.

58. Moseley CF. Leg-Length Discrepancy. In:Morrissy RT, Weinstein SL, editors. Lovell \& Winter's Pediatric Orthopaedics, vol. 2. $6^{\text {th }}$ edition. Philadelphia (PA): Lippincott Williams \& Wilkins; 2006. P. 1234-36. 